\title{
Are Low- and Middle-Income Countries Becoming the Victim of Western Debates About Breast Screening?
}

To the Editor:

Recently, two important initiatives took place to further increase quality of breast cancer (BC) screening and treatment, also in other than high-income countries. In Batumi, Georgia, the 1st International Black Sea Conference on cervical and BC screening was held on 10th and 11th September 2009 with participants from Armenia, Azerbaijan, Bulgaria, Georgia, Moldova, Romania, Turkey, and Ukraine. By exchanging experiences, ideas and the scientific evidence available, plans to further improve implementation of breast (and cervical) cancer screening were debated and formed.

From 24-27 October 2009, the 15th Annual Multidisciplinary Symposium on Breast Disease was held in Cairo with a special summit on health care disparities in developing countries. With thousands of people running the "race for cure" at the Giza pyramids, around 600 participants at the symposium, the presence of ambassador Nancy Brinker of the Susan G Koomen For The Cure and her interview for CNN, the importance of $\mathrm{BC}$ prevention got international and high profile attention again. Not least to say, due to the excellent organization and programme directed by Shahla Masood, the editor of The Breast Journal.

The programme reflected nicely the integrated approach in BC care: primary prevention, screening and treatment, and palliative care, with excellent speakers from high-, middle- and low-income countries. However, the evidence on and fact sheet about BC screening seemed overwhelmed, again, by negative sounds, either called critical issues, challenges or

Address correspondence and reprint requests to: Harry J. de Koning, MD, PhD, Professor of Screening Evaluation, Department of Public Health, Erasmus MC, University Medical Center Rotterdam, PO Box 2040, 3000 CA Rotterdam, the Netherlands, or e-mail: h.dekoning@erasmusmc.nl.

DOI: $10.1111 / j .1524-4741.2010 .00926 . x$

(C) 2010 Wiley Periodicals, Inc., 1075-122X/10

The Breast Journal, Volume 16 Number 4, 2010 442-444 controversies, as was aired recently again both on this and the other side of the Atlantic (1-3).

Screening has always been highly controversial, partly because the procedure is for seemingly healthy people, for whom the benefit should be clear. Evidence of this benefit is, however, for the group as a whole. At the individual level, prediction of who will benefit and who will suffer more harm than good is impossible. The balance between favorable and unfavorable effects is delicate (4).

Of course, it is not likely to involve large-scale mammography as a screening test in low-resources countries, but the debate about mammography screening in Western countries seemed to question and lead to disbelief about the benefits of BC screening in general. That is simply wrong.

Whether earlier detection and treatment of BC result in health benefits was hypothesized in the $1960 \mathrm{~s}$ (5). Large clinical series then showed that for women extensively treated but with relatively large tumors the chance of distant metastases was significantly higher even 25 years after primary treatment (6). Horak showed the biological concept of this: with growth of the tumor, angiogenesis increases with increasing chances of tumor spread to lymph nodes and beyond (7). Removal of the tumor before such critical points of angiogenesis might then mean a higher cure rate.

Randomised controlled trials on mammography screening during 1960-1980 confirmed the benefits of earlier detection and treatment by showing a $25 \%$ reduction in BC mortality in invited women aged 50 and over compared to a control group (8). Also, in practice, numerous case-control studies showed that screened women have a $30-40 \%$ reduced risk in dying from the disease (9), although case-control studies of screening may be biased by the fact that women who have been screened may have been self-selected (showing a favorable outcome independent of screening). This hampers standard evaluations when largescale breast screen programmes are running, but we 


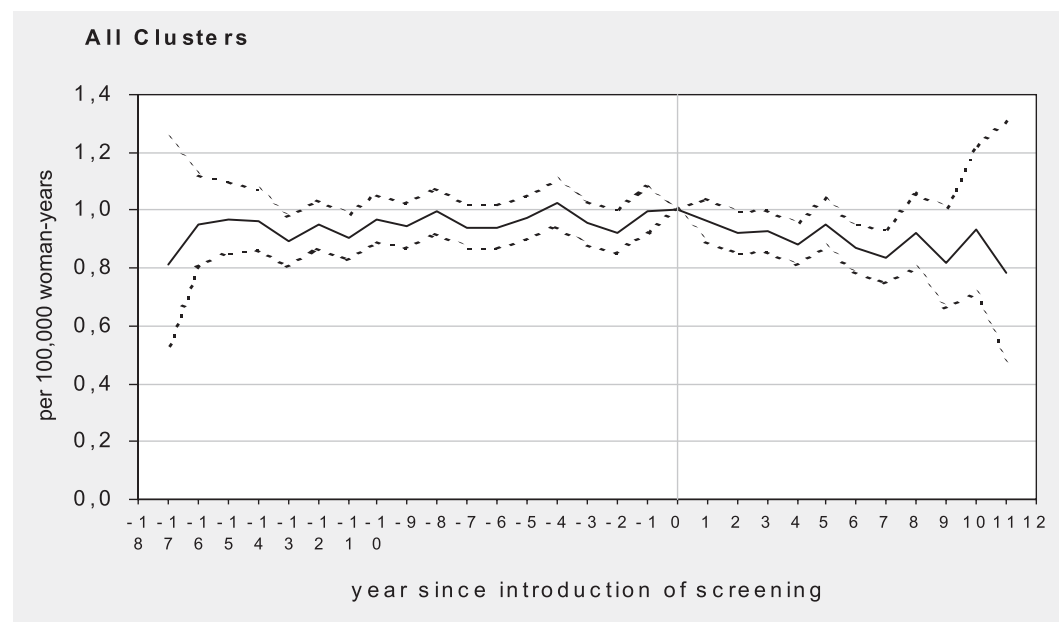

Figure 1. Relative rates of breast cancer by year since introduction of screening in municipalities for age groups $55-74$ years in the Netherlands (Otto et al., Initiation of population-based mammography screening in Dutch municipalities and effect on breast-cancer mortality: a systematic review. Lancet 2003;361(9367):1411-17; reproduced with permission from Elsevier).

elegantly showed that in the Netherlands the start of screening in the municipality changed the annual increase in BC mortality from 0.3 per 100,000 increase per year towards a 1.7 per 100,000 decrease per year (10; Fig. 1). Model exercises showed that roughly $50 \%$ of the decline in BC mortality in the US was likely to be due to the mammography dissemination between 1975 and 2000 (11).

So, there should be no doubt that high quality mammography screening (followed by treatment of early stage cancer) substantially reduces BC mortality in a population. Unfortunately, trials on teaching breast self examination have failed to show a beneficial effect on BC mortality (8). For low- and middle-income countries clinical breast examination (CBE) may be an appropriate alternative to mammography. There is only one randomised controlled trial reported, the Canadian National Breast Screening Study that invited randomised women for clinical breast exams performed by highly trained nurses and the other group for clinical breast exams and mammography (12). Since the trial did not have a control arm without screening tests offered, one has to estimate to what the stages (and stage shift) produced by the clinical breast exams compares to. By detailed mathematical modeling Rijnsburger estimated the CBEs might have produced a $20.5 \%$ BC mortality difference compared to a (nonobserved) control situation without screening (13).

In many middle-income countries $\mathrm{BC}$ incidence is steadily increasing due to aging of the population and a remarkable change in risk factors (14). At the same time, BC is often diagnosed at a late stage. So it means that two prerequisites of considering screening and earlier detection are met.

Especially this worse clinical stage distribution may be one of the main reasons why breast screening, e.g., by clinical exams may still be cost-effective in low-resource and low-incidence countries. The shift attainable by screening may result in important

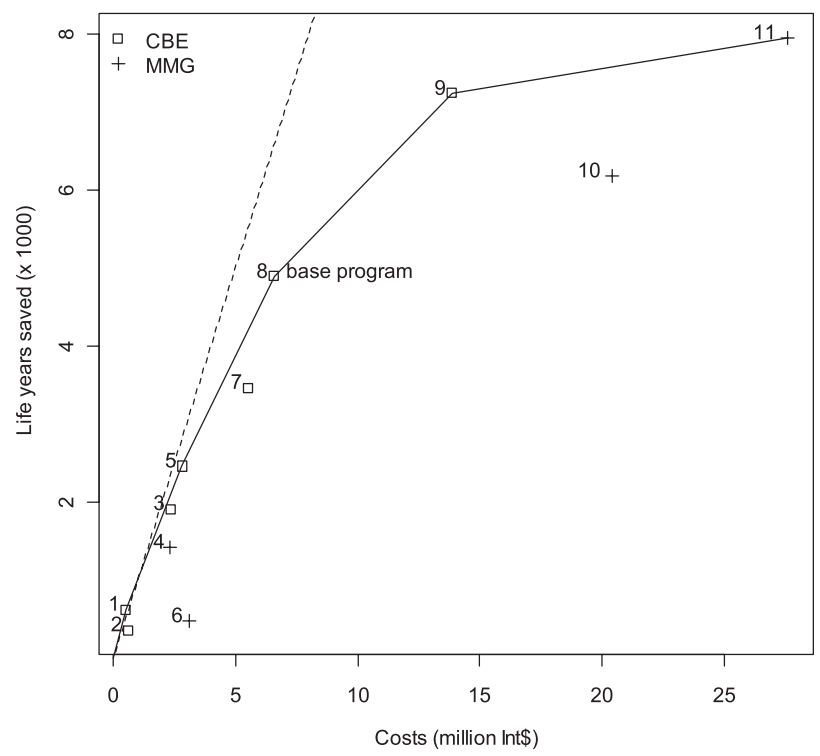

Figure 2. Differential costs and effects of breast cancer screening programs, discounted at 3\% per year (based on Okonkwo et al., $\mathrm{JNCl}$ 2009). The dashed line indicates a cost-effectiveness ratio of Int.\$1000 per life year saved, and the solid line indicates the efficient frontier. The numbers refer to the programs in the original paper (Okonkwo et al., JNCl 2009). 
health benefits, if high quality early treatment is available. For India, we found that screening by clinical breast exams every 2 years for women aged 40-60 might lead to a $16.3 \%$ reduction in BC mortality at 6.6 million Int. $\$$ cost (15). Although there is not one guideline applicable to all countries, CBE screening should seriously be considered in many countries. Figure 2 shows the so-called efficient frontier of breast screen scenarios in India. It shows that programmes with clinical breast exams are cost-effective. This does not mean advising inferior technology for low-income countries; this means achieving important health benefits for the resources available. Of course, the mortality results in the running India trial are eagerly awaited (16), but in the mean time pilot studies performing CBE screening could be gradually implemented. Any new feasible technology or policy changes could perhaps be built on that.

Many steps have to be taken still, both in breaking cultural barriers, in increasing knowledge and fighting misconceptions. There are unfortunately numerous misconceptions: some think the breast is a vital organ and some think cancer is a contagious disease. There are cultural barriers, e.g., in the costumes and clothing hiding any clear visible abnormalities, in the fear women will loose their husbands when loosing their breast and therefore income, women feeling not being a woman anymore and in practical issues like transportation to a screening center as a woman. Unfortunately, also some health care providers are still not equipped both physically nor knowledgeable.

It will be far from easy to start breast screening by clinical breast exams in low-resource countries. It will be challenging to use the culture positively. Tailored out-reach community services, one-stop clinics and emphasis on both public education and health care professionals education will be crucial to "win the race". These initiatives are crucial to pave the roads. And let developing countries not make the same mistake to be confused and stopped in their progress by Western debates about the benefits of breast screening. When you don't know where you are going, every road will take you there (adapted from Alice in Wonderland).
Harry J. de Koning, MD, PhD

Department of Public Health, Erasmus MC, University Medical Center Rotterdam, PO Box 2040, 3000 CA Rotterdam, the Netherlands

\section{REFERENCES}

1. Jørgensen KJ, Gøtzsche PC. Overdiagnosis in publicly organised mammography screening programmes: systematic review of incidence trends. Br Med J 2009;339:b2587.

2. Woloshin S, Schwartz LM. Numbers needed to decide [Editorial]. J Natl Cancer Inst 2009;101:1163-65.

3. Gigerenzer G, Mata J, Frank M. Public knowledge of benefits of breast and prostate cancer screening in Europe. J Natl Cancer Inst 2009;101:1216-20.

4. de Koning HJ. Assessment of nationwide cancer-screening programmes. Lancet 2000;355:80-1.

5. Ingleby $\mathrm{H}$, Gershon-Cohon J, eds. Comparative Anatomy, Pathology and Roentgenology of The Breast. Philadelphia: University of Pennsylvania, 1960.

6. Koscielny S, Tubiana M, Lê MG, et al. Breast cancer: relationship between the size of the primary tumour and the probability of metastatic dissemination. Br J Cancer 1984;49:709-15.

7. Horak ER, Leek R, Klenk N, et al. Angiogenesis, assessed by platelet/endothelial cell adhesion molecule antibodies, as indicator of node metastases and survival in breast cancer. Lancet 1992;340:1120-24.

8. IARC. Handbooks of Cancer Prevention. Vol. 7: Breast Cancer Screening. Lyon, France: IARC, 2002, p. 248.

9. Schopper D, de Wolf C. How effective are breast cancer screening programmes by mammography? Review of the current evidence. Eur J Cancer 2009;45:1916-23.

10. Otto SJ, Fracheboud J, Looman CW, et al. Initiation of population-based mammography screening in Dutch municipalities and effect on breast-cancer mortality: a systematic review. Lancet 2003;361:1411-17.

11. Berry DA, Inoue L, Shen Y, et al. Modeling the impact of treatment and screening on U.S. breast cancer mortality: a Bayesian approach. J Natl Cancer Inst Monogr 2006;36:30-6.

12. Miller AB, To T, Baines CJ, Wall C. Canadian National Breast Screening Study-2: 13-year results of a randomized trial in women age 50-59 years. J Natl Cancer Inst 2000;92:1490-99.

13. Rijnsburger AJ, van Oortmarssen GJ, Boer R, et al. Mammography benefit in the Canadian National Breast Screening Study-2: a model evaluation. Int J Cancer 2004;110:756-62.

14. Parkin DM, Sitas F, Chirenje M, Stein L, Abratt L, Wabinga H. Part I: Cancer in Indigenous Africans-burden, distribution, and trends. Lancet Oncol 2008;9:683-92.

15. Okonkwo Lamberts Q, Draisma G, der Kinderen A, Brown M, de Koning HJ. Breast cancer screening policies in developing countries: a cost-effectiveness analysis for India. J Natl Cancer Inst 2008;100:1290-300.

16. Mittra I, Baum M, Thornton H, Houghton J. Is clinical breast examination an acceptable alternative to mammographic screening? Br Med J 2000;321:1071-73. 